\title{
Variation in Parameters of Ambient Air Quality in National Capital Territory (NCT) of Delhi (India)
}

\author{
Anunay A. Gour', Santosh K. Singh'1, Sushil K. Tyagi², Anubha Mandal1 \\ ${ }^{1}$ Department of Environmental Engineering, Delhi Technological University (Formerly Delhi College of \\ Engineering), Delhi, India \\ ${ }^{2}$ Central Pollution Control Board (CPCB), Delhi, India \\ Email: anunaygour@live.in
}

Received 29 October 2014; revised 30 November 2014; accepted 16 December 2014

Copyright (C) 2015 by authors and Scientific Research Publishing Inc.

This work is licensed under the Creative Commons Attribution International License (CC BY).

http://creativecommons.org/licenses/by/4.0/

(c) (i) Open Access

\begin{abstract}
Air Pollution is an escalating problem worldwide fuelled by increasing anthropogenic activities, speedy development, rapid industrialization, transportation, superfluous use of fossil fuel consumption, increasing global power needs, etc. Also the diverse meteorological factors influence our environment to a great extent. Population explosion has led to remarkable increase in vehicular population. The use solely depends upon the lifestyle of the citizen. Any change in the lifestyle has a remarkable effect on the air we breathe. A comprehensive database for pollution levels from the year 2006 to $\mathbf{2 0 1 0}$ was analyzed for a main traffic intersection and a non-traffic area in Delhi (India). The paper asserts that pollutant concentration levels on weekend are lower than those on weekdays (increase on Sundays with respect to weekdays is CO 2.98 times, PM2.5 1.18 times, NO 1.62 times, $\mathrm{NO}_{2} 5.76$ times, $\mathrm{SO}_{2} 1.27$ times and $\mathrm{O}_{3} 1.15$ times). The pollution levels have been found to attenuate on public holidays and weekends. Pollution can hence be related to the weekly cycle of human activities. Pollutions due to vehicular emissions on roads, rails, air or water all serve as major sources of pollution. Hence, viably possible solutions for pollution control can also be achieved by controlling the magnitude of traffic flow on roads.
\end{abstract}

\section{Keywords}

Ambient Air Quality, Emission, Seasonal Variation, Weekend Effect, Delhi 


\section{Introduction}

The temporal variation of concentration of pollutant throughout the day varies with the influence of local wind parameters such as direction, speed and other meteorological aspects. On the other hand, changing patterns of vehicular traffic and industrial activities also act as a factor for variation in pollution levels. Authors such as Blanchard et al. [1], Murphy (2008) et al. [2], Fujita et al. [3], Gour et al. [4], Murphy (2007) et al. [5] and Kakoli et al. [6] note that weekly cycle of activities of population explains divergent temporal variation in pollution levels from weekdays (Monday to Friday) to weekend (Saturday and Sunday). The paper attempts to carry out an assessment of $24 \mathrm{~h}$ daily average concentration of six major pollutants for a period of five years (from 2006 to 2010). It exhibits Weekly \& Seasonal Variation, Weekday-Weekend differences in concentration of pollutants, Variation in ambient air quality on Public Holidays, i.e. the holiday effect, Comparison of Annual average concentration and National Ambient Air Quality Standards (NAAQS), and Comparison of pollutant levels at a Traffic Area and a Non-Traffic Area.

\section{Pollution Emission}

The human population explosion has led to a significant increase in the vehicular population. The urban population of India has tripled within a period from 1951 to 1991, from 62.5 million to 217.6 million; correspondingly the vehicle population has increased almost 124 times from 0.3 million to 37.2 million (Ministry of State Transport 2000). Fossil fuel driven vehicles are the significant contributors to pollution. A major section of population uses private vehicles (diesel, petrol and compressed natural gas driven) such as two-wheeled vehicles and cars including the high fuel consuming Sports Utility Vehicles (SUVs), Multiple Utility Vehicles (MUVs), trucks, etc. However, mass rapid transportation modes such as metro rail and buses and railways continue to be the most popular means of transportation for intra-city travel; they cater to about $60 \%$ of the total commuting requirements. Private vehicles account for $30 \%$ of the total demand for transportation, while the rest of the demand is met largely by auto-rickshaws and taxis. Reddy and Venkataraman [7] and Abera et al. [8] note that the pollutants like $\mathrm{CO}$ and $\mathrm{NO}_{\mathrm{x}}$ emanate from automobile exhausts, whereas use of coal based fuels causes heavy emissions of $\mathrm{SO}_{2}$. Murphy (2008) et al. [2] and Rosibeto et al. [9] find that the levels of $\mathrm{O}_{3}, \mathrm{NO}_{\mathrm{x}}$ and particulate matter are an issue of concern in the urban environment. The variation in concentration of such pollutants strongly relates to the pattern of human activities in the city. Khaiwal et al. [10] report that implementation of compressed natural gas $(\mathrm{CNG})$ as fuel in public transport in Delhi has mitigated the major pollutants, but increased the emission of benzene and other organic compounds. Consumption of fuels for automobile and industrial purposes, factors related to individual's lifestyle, working and non-working environment, religious and cultural practices, festivities, etc. act as major factors for variation in ambient air quality in the metro. This explicitly expresses an idea about the magnitude by which the pollution can be mitigated by altering the lifestyle or some of the habits of the population. It can also be resolved that pollution mitigation is a function of public willingness and proper understanding by the masses without which it is impossible to tackle this threat.

Authors like Chhabra et al. [11], Maureen et al. [12], Barman et al. [13] and Ramalingaswami et al. [14] report that pollutants such as carbon monoxide (CO), particulate matter (10 $\mu$ and $2.5 \mu$ size), nitrogen oxide (NO), nitrogen dioxide $\left(\mathrm{NO}_{2}\right)$ and sulphur dioxide $\left(\mathrm{SO}_{2}\right)$ cause health effects related to lungs, throat, cardiovascular disorders, etc. Blanchard et al. [1], Murphy (2008) et al. [2], Fujita et al. [3], Gour et al. [4], Murphy (2007) et al. [5], Kakoli et al. [6], Reddy and Venkataraman [7], Stephens et al. [15] and Debaje et al. [16] find that pollutant concentrations surge on weekdays and reduce on weekend. The data also reveal that ozone $\left(\mathrm{O}_{3}\right)$ increases on weekend especially on Sundays contrary to decreasing concentration of other pollutants like $\mathrm{NO}_{\mathrm{x}}$ and some hydrocarbons which act as its precursors. Such observations are also referred to as "Weekend effect" by Blanchard et al. [1], Fujita et al. [3], Gour et al. [4], Murphy (2007) et al. [5], Rosiberto et al. [9], Stephens et al. [15], Debaje et al. [16] and Tan et al. [17]. On weekend, the reduced PM and aerosols result in more inward solar radiation accompanied with the precursor $\mathrm{NO}_{\mathrm{x}}$ accumulated over the week aids the ozone production. At some instances, concentration of Ozone increases on weekend irrelevant of the concentrations of its precursors. Seasonal variations during summer, winter, North East Monsoon (NE Monsoon) and South West Monsoon (SW Monsoon) over weekday-weekend differences were also studied. Factors such as diurnal temperature range, daily maximum temperature, daily precipitation, annual precipitation and wind speed and seasonal maximum and minimum temperature influence the pollutant concentration. 


\section{Methodology}

\subsection{Description of Study Area}

National Capital Territory of Delhi is one of the largest metropolises by area and population in the world. It has population more than 12.25 million inhabitants in the territory. There are nearly 22.2 million residents in the greater National Capital Region (NCR) urban area which includes Noida, Greater Noida, Ghaziabad, Gurgaon and Faridabad along with other smaller nearby towns. There are 6.5 million registered vehicles in the city, which is the highest in the world among all cities, while the NCR has 11.2 million vehicles. Public transport in the metropolis includes the Delhi Metro, the Delhi Transport Corporation mass transit bus system, auto-rickshaws, cycle-rickshaws and taxis.

The area of study, ITO Station at R.C. Aggarwal Square, Bahadur Shah Zafar Marg, is one of the prime commercial locations with numerous corporate and government offices in its vicinity, see Figure 1. Air quality here is greatly affected by the heavy vehicular traffic; hence it turns out to be a principle site for such comparative studies. Ambient air here is also influenced by emissions from two coal-fired power generation stations namely, Pragati Thermal Power Plant (Indraprastha) and Badarpur Thermal Power Plants (Badarpur). DCE Station located inside Delhi college of Engineering was selected as a non-traffic area for some more comparisons.

\subsection{Data}

The paper analyses $24 \mathrm{~h}$ daily average concentrations of six pollutants, namely, $\mathrm{CO}, \mathrm{NO}, \mathrm{NO}_{2}, \mathrm{SO}_{2}, \mathrm{O}_{3}, \mathrm{PM}_{(10}$ $\mu$ and $2.5 \mu$ ) for the period of 5 years from 2006 to 2010 at the National Ambient Air Quality Monitoring Station (NAAQMS) of Central Pollution Control Board (CPCB) at R.C. Aggarwal Square near Income Tax Office (ITO) on Bahadur Shah Zafar Marg, New Delhi.

\section{Results and Discussions}

Statistical and graphical analysis of the $24 \mathrm{~h}$ data pertaining to the period of 2006 to 2010 are discussed in the following headings:

- Weekday and Weekend Comparison;

- Weekly Variation;

- 24 H Annual Average (Traffic vs. Non-Traffic Area);

- Average Annual Pollution Levels;

- Average Seasonal Variation;

- Public Holidays.

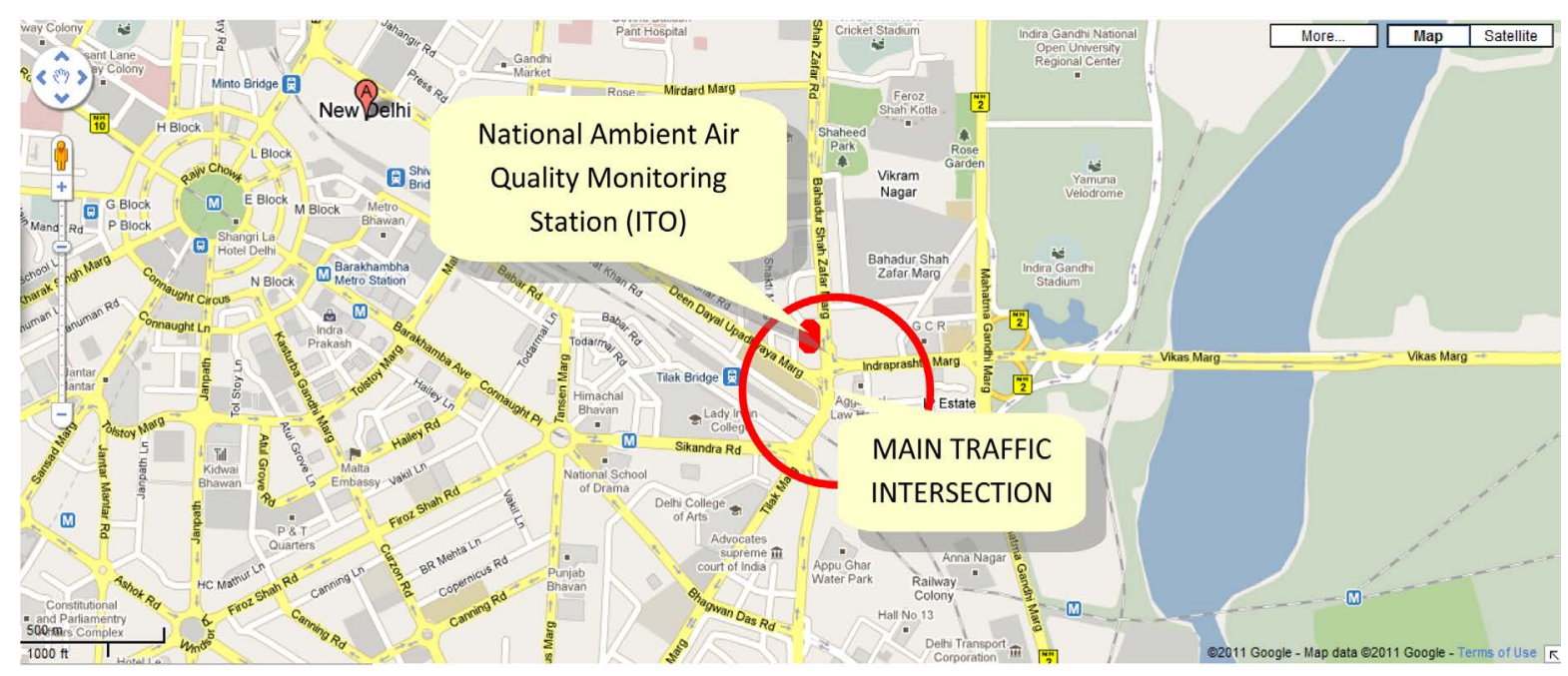

Figure 1. NAAQMS ITO station at R.C. Aggarwal Square, Bahadur Shah Zafar Marg, New Delhi, India (source: Google maps). 


\section{A. A. Gour et al.}

\subsection{Weekday and Weekend Comparison}

Figure 2 shows the $24 \mathrm{~h}$ average concentration of the parameters plotted on a time scale of consecutive seasons from years 2006 to 2010 on $\mathrm{x}$-axis and concentration of the respective parameters represented by the graphs of weekdays (red) and weekends (cyan). Seasonal grouping of data facilitates analysis with similar meteorological conditions and hence can be useful in studying the season-induced variations in pollution. The observations are as follows:

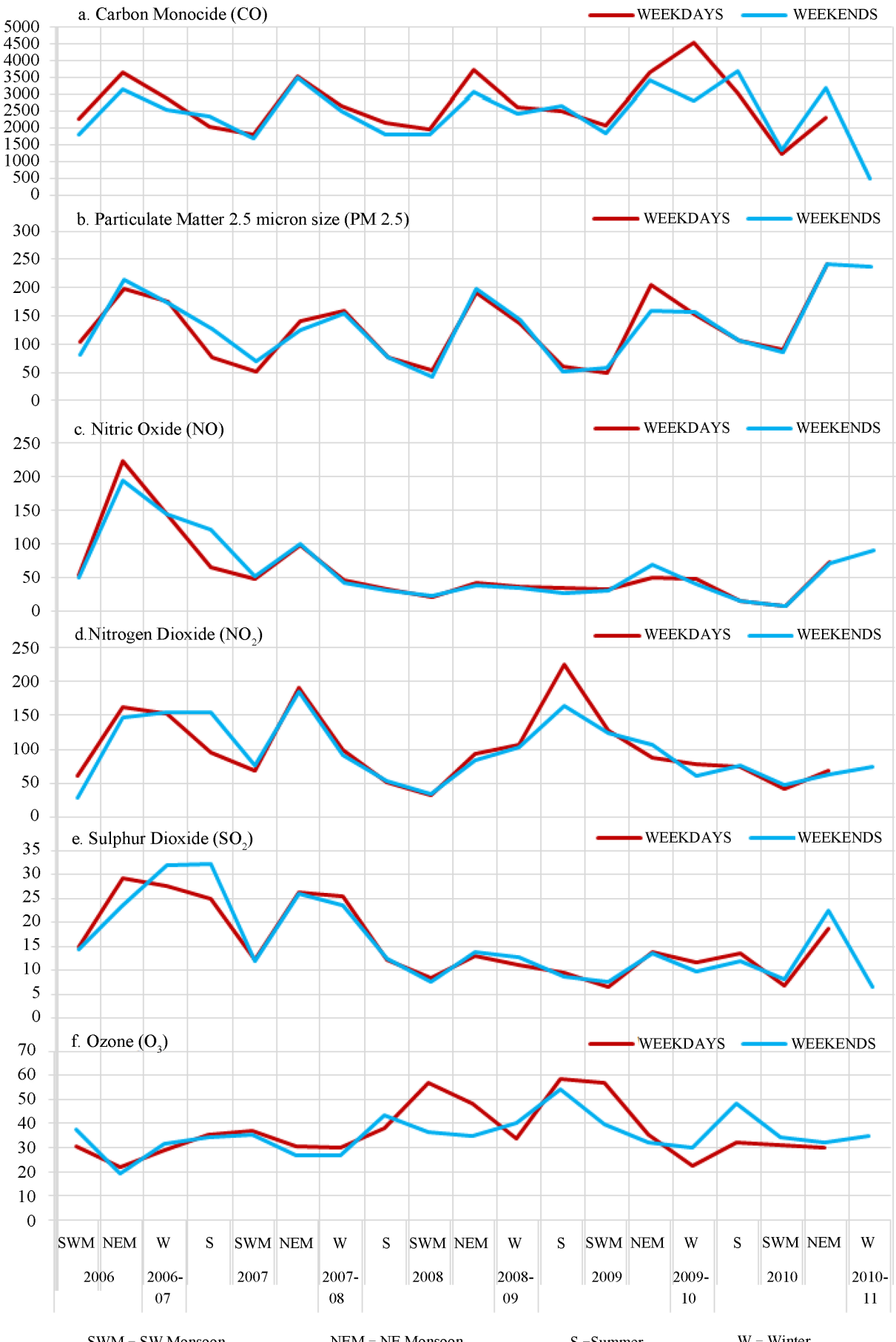

SWM - SW Monsoon

NEM - NE Monsoon

S-Summer

W - Winter

Figure 2. Weekday-weekend comparison w.r.t. seasons (Gour et al. [4]). 
Carbon Monoxide: It is evident that average weekday concentration of carbon monoxide, as occurrence of co-ordinates of individual temporal ranges show a well defines sequence (cyan-red), i.e. pollution levels on Weekdays is more than that on Weekends. As substantiated by existing data from 2006 to 2010, on an average, concentration of $\mathrm{CO}$ as on weekdays is 1.75 times as that on Saturdays and is as much as 2.98 times as that on Sundays. CO being one of the substances that are agelessly related to vehicular exhausts very well demonstrated the impact of vehicles over the environment. A well-defined pattern exist, with highest concentration during NE Monsoon is seen which gradually falls through winter and summer and reaches its lowest in the season of SW Monsoon. Year 2010 shows CO with 1.5 times more concentration than that fixed for national ambient air. CO in automobiles is produced as a result of incomplete combustion of fuel; possible due to inadequate oxidation i.e. in shortage of oxygen. Mitigation of vehicular $\mathrm{CO}$ can be guaranteed by facilitating complete combustion of fuels.

Particulate Matter is the category of pollutants which causes major respiratory track related disorders like asthma, etc. Apart from the natural sources transportation, stationary combustion and industrial and traffic-related fugitive emissions, street dust etc. can be ways of particulate pollution. The concentration of particulate matter here, by and large, was found to be similar during weekends and weekdays under the influence of particulates like fly-ash and dust from the two thermal power generation plants nearby. As substantiated by existing data from 2006 to 2010, on an average, concentration of PM2.5 as on Weekdays is 1.12 times as that on Saturdays and is as much as 1.18 times as that on Sundays. Similar to CO, PM also shows a well-defined pattern with highest concentration during NE Monsoon is seen which gradually falls through winter and summer and reaches its lowest in the season of SW Monsoon. Particulates are seen to rise in year 2010. The average concentration of PM2.5 throughout the period (2006-2010) studied, had always been above by about 3.34 times the NAAQS permissible limit and hence can be said as an area of greater vitality for the need to mitigate pollution.

Oxides of Nitrogen are the precursors of both acid precipitation and ozone, each of which is blamed for injury to plants. It is nitrogen oxide that absorbs sunlight, initiating the photochemical processes that produce nitric acid, which may precipitate with the rainfall. As substantiated by existing data from 2006 to 2010, on an average, concentration of NO as on Weekdays is 1.56 times as that on Saturdays and is as much as 1.62 times as that on Sundays. Also the concentration of $\mathrm{NO}_{2}$ as on Weekdays is 1.28 times as that on Saturdays and is as much as 5.76 times as that on Sundays. Similar to $\mathrm{CO}$ and $\mathrm{PM}, \mathrm{NO}_{\mathrm{x}}$ also shows a well-defined pattern with higher concentration during NE Monsoon is seen which gradually falls through winter and summer and reaches its lowest in the season of SW Monsoon. After the high of 2006, level of NO lowered from 2007 to 2009 but soared again in year 2010, whereas $\mathrm{NO}_{2}$ had a high in summer of 2009 .

Sulphur Dioxide, being an integrated component of fossil fuels, leads to emission amount of oxides of sulphur into atmosphere. Validated by the data from 2006 to 2010, on an average, concentration of $\mathrm{SO}_{2}$ as on Weekdays is 1.31 times as that on Saturdays and is as much as 1.27 times as that on Sundays. Similar to CO, $\mathrm{PM}$ and $\mathrm{NO}_{\mathrm{x}}, \mathrm{SO}_{\mathrm{x}}$ also shows a well-defined pattern with higher concentration during NE Monsoon is seen which gradually falls through winter and summer and shows steep fall with the onset of SW Monsoon reaches its lowest in this season. The pattern of $\mathrm{SO}_{\mathrm{x}}$ from 2006 to 2010 is shows a falling trend.

Ozone shows somewhat unpredictable behavior as per the data from 2006 to 2010, on an average, concentration of $\mathrm{O}_{3}$ as on Weekdays is 1.22 times as that on Saturdays and is as much as 1.15 times as that on Sundays. Compared to other pollutants, ozone shows contrary concentrations, which remain similar with some peaks at Sundays. Contrary to $\mathrm{CO}, \mathrm{PM}$ and $\mathrm{NO}_{\mathrm{x}}, \mathrm{SO}_{\mathrm{x}}$ which shows higher concentration in NE Monsoon gradually falls through winter and summer and attain their lowest in SW Monsoon, Ozone shows lowest levels in NE Monsoon increases through Winter and Summer and reaches its highest levels in SW Monsoon. Ozone shows significant influence of solar radiation and obliquity to sun. The rain-washed air during SW Monsoon gives way to increased insolation and causes increased photo-oxidation of $\mathrm{NO}_{\mathrm{x}}$ and $\mathrm{HCs}$. It has been observed that ozone shows higher levels where NOx shows lower levels and vice versa. Years 2008 and 2009 show higher levels of $\mathrm{O}_{3}$.

\subsection{Weekly Variation}

It was observed that the concentration of the pollutants such as $\mathrm{CO}, \mathrm{NO}, \mathrm{NO}_{2}$ drastically falls as we reach Sundays i.e. towards the end of the week. The changing pattern of vehicular usage of individuals in urban areasshows a cyclic variation of pollutants with a periodicity of 1 week [14]. Sunday being a holiday becomes the day for rest and entertainment for the population; hence it is envisaged with clearer roads, lesser traffic flow, hence 
less pollution as compared to that on other days. On Sundays, it is evident that the concentration of pollutants even at the normal peak times is far below the average weekday's level of pollutants. Similar trend can be observed as most of the government offices and private offices observe a half-day at work on Saturday; hence rendering a pollution level slightly above than that on Sundays but assertively below the pollution levels on Weekdays.

\subsection{H Annual Average (Traffic vs. Non-Traffic Area)}

Figure 3 shows the effect of the vehicular emission over the concentration of pollutants, taking into consideration the Income Tax Office (ITO) station, which is located at the main traffic intersection, is under heavy traffic flow throughout the day. Whereas, Figure 4 shows DCE Station is located inside Delhi College of Engineering campus where a negligible traffic with very restricted entry of vehicles exists and a low influence of some small scale industries nearby. The principal emissions from vehicles include $\mathrm{CO}$ and $\mathrm{SO}_{2}$, combustion and heating also cause formation of $\mathrm{NO}_{2}$. It was found that level of $\mathrm{CO}$ is alarmingly high at ITO whereas below permissible limit at DCE. Differences exists in concentration of ozone, which shows higher pollution levels at the DCE station whereas the heavy traffic area shows relatively low levels of ozone. This can be explained as; a highly polluted area has an envelope of dust and pollutant gases which retards the solar radiation which in turn slows down photo-oxidation of $\mathrm{NO}_{\mathrm{x}}$. Hence, rather being below NAAQ Standard's permissible value, DCE shows higher levels of ozone than that at ITO. A general falling trend is visible in $24 \mathrm{~h}$ annual average from 2006 to 2010.

\subsection{Average Annual Pollution Levels}

The pattern showed by the annual daily averages shows increasing levels of $\mathrm{CO}$ and $\mathrm{PM}$, whereas a falling trend in terms of $\mathrm{SO}_{2}, \mathrm{NO}_{2}$ and $\mathrm{O}_{3}$, despite of increasing number of vehicles on road. This can be due to new motor regulations, use of CNG, catalytic convertors, etc. Increased influence of the surrounding (e.g. coal powered power stations) leads to rise in level of particulates and $\mathrm{CO}$, although, a general fall of consecutive year's pollution levels is evident from the data studied.

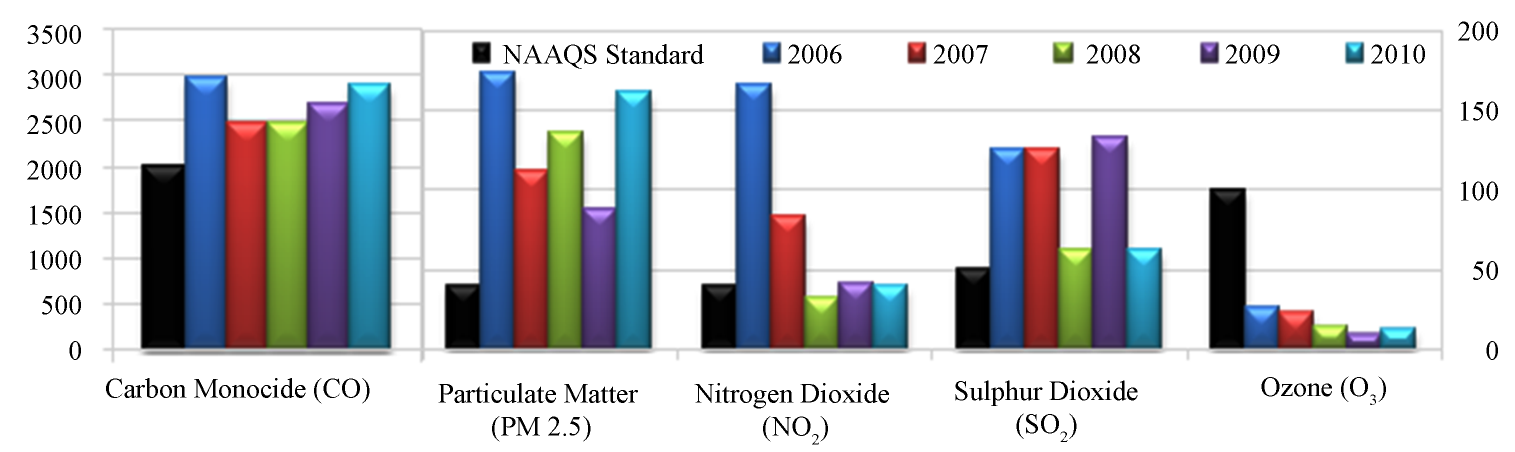

Figure $3.24 \mathrm{~h}$ annual average concentration of pollutants at a traffic intersection (ITO Station).

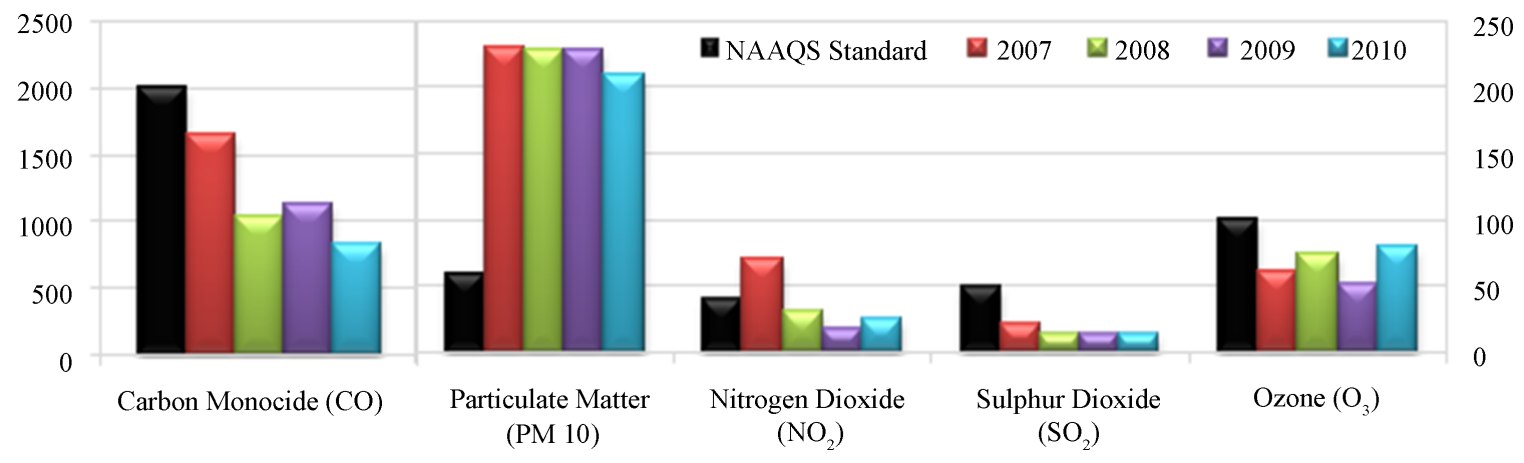

Figure 4. $24 \mathrm{~h}$ annual average concentration of pollutants at a non-traffic area (DCE Station). 
Average concentration of pollutants from 2006 to 2010 shows levels of $\mathrm{CO}, \mathrm{PM}$ and $\mathrm{NO}_{2}$ persistently violating the permissible limits as assumed in the National Ambient Air Quality Standard (NAAQS) as shown in Table 1 . CO exceeds by $30 \%$ more than NAAQS, similarly, PM2.5 shows $220 \%$ excess concentration. The concentration of $\mathrm{NO}$ is in excess by more than $50 \%$ of its permissible value, concentration $\mathrm{SO}_{2}, \mathrm{O}_{3}$ and $\mathrm{PM} 10$ were found to be lower than limits.

\subsection{Average Seasonal Variation}

Figure 5 observes that maximum concentrations of pollutants occur during winter season, as the atmosphere is quite dry in the winter and also due to the lowered mixing height; because the atmospheric lid, i.e. tropopause or the zone of temperature inversion, is formed at the lower level as compared to any other seasons. Similarly it can be stated that since the tropopause is formed at a relatively higher altitude during summers, the atmosphere gets an increased volume of air for dispersion of pollutants. The data, as studied, show near concentration of pollutants between winter and summer seasons.

This demonstrates that in reality, summers have higher level due to greater dispersion of pollution than in winters. The inter-annual seasonal daily averages confirms that season of SW Monsoon shows a significant fall in concentrations of pollutants as compared to higher concentrations in winter. It also shows similar levels during summer and NE Monsoon seasons. This can be explained on the grounds that pollutants possibly get absorbed and precipitated with rain-water during the SW Monsoon season. On a divergent note, the concentration of ozone shows slight increase in level during SW Monsoon, this increase can be related to clarity of atmosphere and fair insolation. Sunlight splits the nitrogen dioxide into nitric oxide and atomic oxygen, which combines with molecular oxygen to yield ozone, as in Reactions 1 and 2 as followings:

$$
\begin{gathered}
\mathrm{NO}_{2}+\text { sunlight } \rightarrow \mathrm{NO}+\mathrm{O} \\
\mathrm{O}+\mathrm{O}_{2} \rightarrow \mathrm{O}_{3}
\end{gathered}
$$

Reaction 1

Reaction 2

These reactions are rather fast so $\mathrm{NO}$ and $\mathrm{NO}_{2}$ cycle, but the sum of their concentration $\left([\mathrm{NO}]+\left[\mathrm{NO}_{2}\right]\right)$ tends to remain fairly constant. Because of this cycling, it is convenient to consider the two chemicals as a group; hence the term $\mathrm{NO}_{\mathrm{x}}$.

\subsection{Public Holidays}

A public holiday (PH) marks the day-off for the Govt. Offices; Central Public Sector Undertaking companies (CPSUs) and other such institutions. The effect of such a leave can be well demonstrated as gazetted holidays

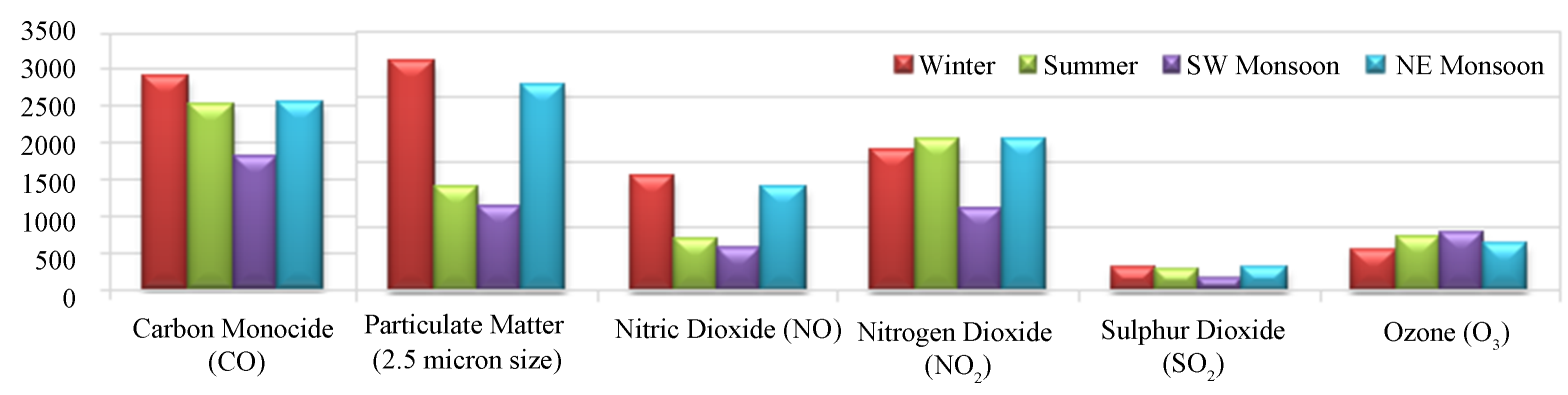

Figure 5. Average seasonal variation of pollutant concentration.

Table 1. $4 \mathrm{~h}$ averages for the period of 2006-2010.

\begin{tabular}{ccccccc}
\hline Parameter & $\mathbf{C O}^{\#}$ & $\mathbf{P M 2 . 5}^{*}$ & $\mathbf{N O}^{*}$ & NO $_{2}^{*}$ & 40 & 50 \\
NAAQS & 2000 & 40 & - & $\mathbf{S O}_{2}^{*}$ & \\
Average & 2608.93 & 127.68 & 61.79 & 97.62 & 100 \\
\hline
\end{tabular}

${ }^{\#}$ Annual $8 \mathrm{~h}$ average; "Annual $24 \mathrm{~h}$ average. 
for the period of 2006 to 2010 (18 gazetted holidays per year) were analyzed and found that if pollution earlier was unity (1) the pollution reduces by at least $4 \%$ for $\mathrm{O}_{3}$ and $\mathrm{PM} 11$ to $14 \%$ for $\mathrm{NO}, \mathrm{CO}$ and $\mathrm{NO}_{2}$ from the pollution levels of the respective parameters in the same week. The pollution levels falls on the PH and again starts rising from the next day.

Figure 6 gives a general idea about the effect of a holiday on pollution; but if the effect of the weekly cycle of human activities over the pollution levels near public holidays is intended to study; it can be done so by grouping the parameters on the PH by the day on which it occurs. Hence all PH were grouped and their averaged 24-h pollution concentration was analyzed. Table 2 analyses the data by representing the factor $(<1=$ "decrease" and vice versa) after comparing the pollution levels for 3 days (i.e. taking earlier level $=1$ or unity) before the $\mathrm{PH}$ on a particular day.

\section{Conclusions}

Comparison of annual average concentration of parameters with respect to NAAQ Standards shows violation from the standard of $\mathrm{CO}, \mathrm{PM}$ and $\mathrm{NO}_{2}$ persistently from 2006 to 2010. It is observed that $\mathrm{CO}$ exceeds by more than $30 \%$ of its permissible value, PM2.5 by $220 \%$; $\mathrm{NO}$ is excess by more than $50 \% ; \mathrm{SO}_{2}, \mathrm{O}_{3}$ and PM10 are found to be within limits. The pattern of the $24 \mathrm{~h}$ annual averages shows increasing levels of carbon-monoxide and particulates, whereas sulphur dioxide, nitrogen dioxide and ozone show a falling trend.

Weekend-Weekday Analysis validates that the emission from vehicular usage by individuals in urban areas shows a cyclic behavior with a periodicity of 1 week. As substantiated by the data from 2006 to 2010, concentration of CO on weekdays is as 1.75 times as that on Saturdays and is as much as 2.98 times as that on Sundays. Concentration of parameters in the year 2010 shows CO with 1.5 times more concentration than NAAQ Standard. Particulates are seen to rise in Year 2010 and their average concentration on Weekdays is as 1.12 times as that on Saturdays and is as much as 1.18 times as that on Sundays. The average concentration of PM2.5 throughout the period (2006-2010) had been found to be 3.34 times more than the NAAQS Standard. NO on weekdays shows as 1.56 times concentration as that on Saturdays and is as much as 1.62 times as that on Sundays. Also the concentration of $\mathrm{NO}_{2}$ on weekdays is as 1.28 times as that on Saturdays and is as much as 5.76 times as that on Sundays. Average concentration of $\mathrm{SO}_{2}$ on weekdays is as 1.31 times as that on Saturdays and is as much as 1.27 times as that on Sundays. The pattern of $\mathrm{SO}_{\mathrm{x}}$ from 2006 to 2010 shows a falling trend. The concentration of ozone on weekdays is 1.22 times as that on Saturdays and is as much as 1.15 times as that on

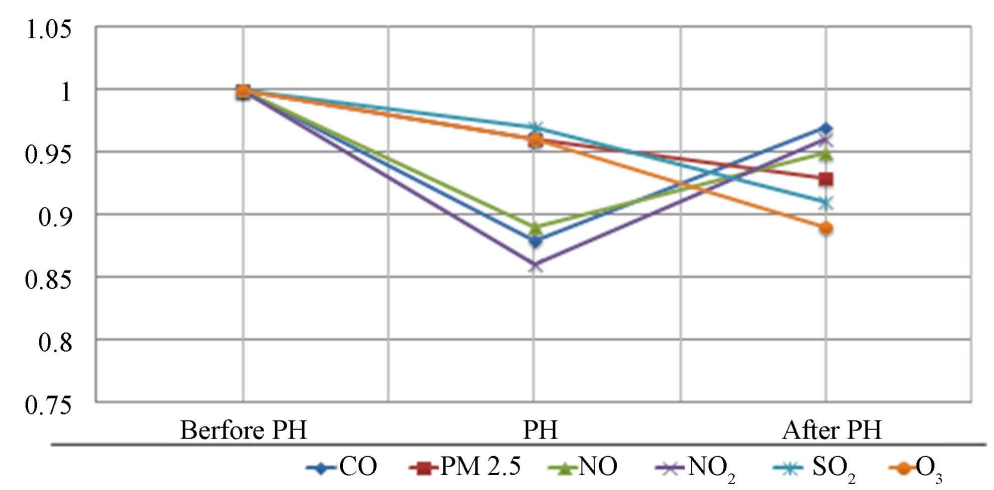

Figure 6. Comparison of pollutant concentration during public holidays.

Table 2. Pollution level comparison on public holidays.

\begin{tabular}{ccccccc}
\hline Aspect & CO & PM2.5 & NO & NO $_{2}$ & $\mathbf{S O}_{2}$ & $\mathbf{O}_{3}$ \\
\hline Before PH & 1 & 1 & 1 & 1 & 1 & 1 \\
On PH & 0.88 & 0.96 & 0.89 & 0.86 & 0.97 & 0.96 \\
After PH & 0.97 & 0.93 & 0.95 & 0.96 & 0.91 & 0.89 \\
\% reduction & 12 & 4 & 11 & 14 & 3 & 4 \\
\hline
\end{tabular}


Sundays. It has been observed that ozone shows higher levels where $\mathrm{NO}_{\mathrm{x}}$ shows lower levels and vice versa. Years 2008 and 2009 show higher levels of $\mathrm{O}_{3}$.

Seasonal Variation Analysis infers an annual cycle in monthly concentration as the trend starts falling from February, gradually extending till the month of August. It attains a rising gradient from August till it reaches the highest in November, then the trend again falls till February. The season of winter in 2010 shows pollutants with higher levels of concentration than those during the preceding years. Parameters such as $\mathrm{CO}, \mathrm{PM}, \mathrm{NO}_{\mathrm{x}}$ and $\mathrm{SO}_{\mathrm{x}}$ generally show higher concentration in NE Monsoon; the concentration gradually falls throughout winter and summer seasons and attains lowest levels in SW Monsoon season. On a contrary note, Ozone shows lowest levels in NE Monsoon, increases throughout winter and summer seasons, and reaches its highest levels in SW Monsoon. Concentration of the parameters in winter can increase by almost 1.61 to 2.69 times concentration in SWM, and similarly by 1.23 to 1.4 times in summer and 1.41 to 2.47 times in NEM. Contrarily, ozone show its minimum levels in winter due to obliquity to sunrays, whereas reaches its maximum in SWM.

Analysis of pollutant concentration on public holidays shows that the pollution levels reduce by at least $4 \%$ for $\mathrm{O}_{3}$ and $\mathrm{PM}$, and up to $11 \%$ to $14 \%$ for $\mathrm{NO}, \mathrm{CO}$ and $\mathrm{NO}_{2}$ from the pollutant concentration levels of the same week. If PH occurs in the start of the week (i.e. on Monday or Tuesday), pollution levels show lower than even weekends. Most pollution is observed if PH occurs on mid-week (Wednesday) or on weekends (Saturdays).

The paper differentiates air pollutant concentration between weekdays and weekends. The observed phenomena of weekend effect and holiday effect provide evidence of impact of human activity on ambient air. Pollution variation corresponds to the pattern of working on weekend and weekdays. Comparative analysis from different aspects shows that vehicular emission largely increases on weekdays and drops down on weekends. Such weekend effect or holiday effect is also seen on public holidays. A general trend of fall in concentration has been found during the season of SW Monsoon. The study also shows, in particular, higher levels of Ozone during weekends. Hence, the cycle of human activities at different periodicities shows their deep influence over environmental health. It can hence be stated that vehicular pollution mitigation is a function of public willingness and understanding without which it is impossible to tackle this menace.

\section{References}

[1] Blanchard, C.L. and Shelley, T. (2006) Weekday/Weekend Differences in Ambient Air Pollutant Concentrations in Atlanta and the Southeastern United States. Journal of Air \& Waste Management, 56, 271-284. http://dx.doi.org/10.1080/10473289.2006.10464455

[2] Murphy, D.M., Capps S.L., Daniel, J.S., Frost, G.J. and White, W.H. (2008) Weekly Patterns of Aerosol in the United States. Atmospheric Chemistry and Physics, 8, 2729-2739. http://dx.doi.org/10.5194/acp-8-2729-2008

[3] Fujita, E.M., Campbell, D.E., William, S., Keislar, R.E., Barbara, Z., Sagebiel, J.C., Wendy, G., Michael, K. and Bowen, J.L. (2002) Weekend/Weekday Ozone Observations in the South Coast Air Basin: Volume II-Analysis of Air Quality Data. Report, National Renewable Energy Laboratory, Desert Research Institute, Division of Atmospheric Sciences, Nevada, USA.

[4] Gour, A.A., Singh, S.K., Tyagi, S.K. and Mandal, A. (2012) Weekday/Weekend Differences in Air Quality Parameters in Delhi, India. IMPACT: International Journal of Research in Engineering \& Technology, 1, 69-76.

[5] Murphy, J.G., Day, D.A., Cleary, P.A., Wooldridge, P.J., Millet, D.B., Goldstein, A.H. and Cohen, R.C. (2007) The Weekend Effect within and Downwind of Sacramento: Part 1: Observations of Ozone, Nitrogen Oxides, and VOC Reactivity. Atmospheric Chemistry and Physics, 7, 5327-5339. http://dx.doi.org/10.5194/acp-7-5327-2007

[6] Karar, K., Gupta, A.K., Kumar, A., Biswas, A.K. and Devotta, S. (2006) Statistical Interpretation of Weekday/Weekend Differences of Ambient Particulate Matter, Vehicular Traffic and Meteorological Parameters in an Urban Region of Kolkata, India. Indoor and Built Environment, 15, 25-245.

[7] Reddy, M.S. and Venkataraman, C. (2002) Inventory of Aerosol and Sulphur Dioxide Emissions from India: I-Fossil Fuel Combustion. Atmospheric Environment, 36, 677-697. http://dx.doi.org/10.1016/S1352-2310(01)00463-0

[8] Kume, A., Charles, K., Berehane, Y., Anders, E. and Ali, A. (2010) Magnitude and Variation of Traffic Air Pollution as Measured by CO in the City of Addis Ababa, Ethiopia. Ethiopian Journal of Health Development, 24, 156-166.

[9] Da Silva Júnior, R.S., De Oliveira, M.G.L. and De Fátima Andrade, M. (2009) Weekend/Weekday Differences in Concentrations of Ozone, NOx, and Non-Methane Hydrocarbon in the Metropolitan Area of São Paulo. Revista Brasiliera de Metrologia, 24, 100-110.

[10] Ravindra, K., Wauters, E., Tyagi, S.K., Mor, S. and Van Grieken, R. (2006) Assessment of Air Quality after the Implementation of Compressed Natural Gas as Fuel in Public Transport in Delhi, India. Environmental Monitoring and 
Assessment, 115, 405-417. http://dx.doi.org/10.1007/s10661-006-7051-5

[11] Chhabra, S.K., Pande, J.N., Joshi, T.K. and Kumar, P. (2001) Air Quality and Health. Workshop on Land Use, Transportation and the Environment, Pune, 3-4 December 2001, 1-24. http://www.deas.harvard.edu/TransportAsia/workshop papers/ChhabraetalFinal2.pdf

[12] Cropper, M.L., Simon, N.B., Anna, A. and Sharma, P.K. (1997) Policy Research Working Paper No. 1860: The Health Effects of Air Pollution in Delhi, India. Development Research Group, The World Bank.

[13] Barman, S.C., Kumar, N., Singh, R., Kisku, G.C., Khan, A.H., Kidwai, M.M., Murthy, R.C., Negi, M.P.S., Pandey, P., Verma, A.K., Jain, G. and Bhargava, S.K. (2010) Assessment of Urban Air Pollution and It's Probable Health Impact. Journal of Environmental Biology, 31, 913-920.

[14] Ramalingaswami, V., Aggarwal, P., Chhabra, S.K., Desai, P., Ganguly, N.K., Gopalkrishnan, K., Kacker, S.K., Kalra, V., Kamat, R., Kochupillai, V., Nag, D., Pande, J.N., Raina, V., Ray, P.K., Saiyed, H., Seth, P.K., Trehan, N. and Wasir, H.S. (1999) Urban Air Pollution. Current Science, 77, 334-336.

[15] Stephens, S., Madronich, S., Wu, F., Olson, J., Ramos, R., Retama, A. and Munoz, R. (2008) Weekly Patterns of Mexico City's Surface Concentrations of CO, NOx, PM10 and $\mathrm{O}_{3}$ during 1986-2007. Atmospheric Chemistry and Physics, 8, 5313-5325. http://dx.doi.org/10.5194/acp-8-5313-2008

[16] Debaje, S.B. and Kakade, A.D. (2006) Weekend Ozone Effect over Rural and Urban Site in India. Aerosol and Air Quality Research, 6, 322-333.

[17] Tan, P.-H., Chou, C., Liang, J.-Y., Chou, C.C.-K. and Shiu, C.-J. (2009) Air Pollution "Holiday Effect" Resulting from the Chinese New Year. Atmospheric Environment, 43, 2114-2124. http://dx.doi.org/10.1016/j.atmosenv.2009.01.037 
Scientific Research Publishing (SCIRP) is one of the largest Open Access journal publishers. It is currently publishing more than 200 open access, online, peer-reviewed journals covering a wide range of academic disciplines. SCIRP serves the worldwide academic communities and contributes to the progress and application of science with its publication.

Other selected journals from SCIRP are listed as below. Submit your manuscript to us via either submit@scirp.org or Online Submission Portal.
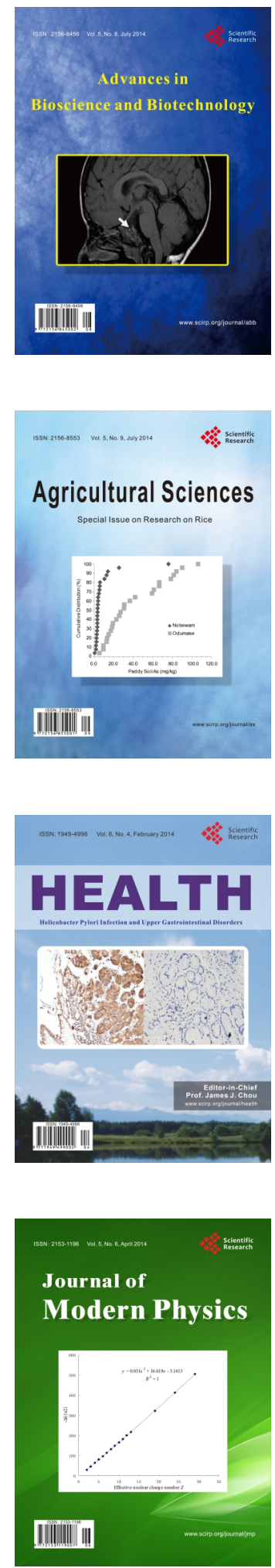
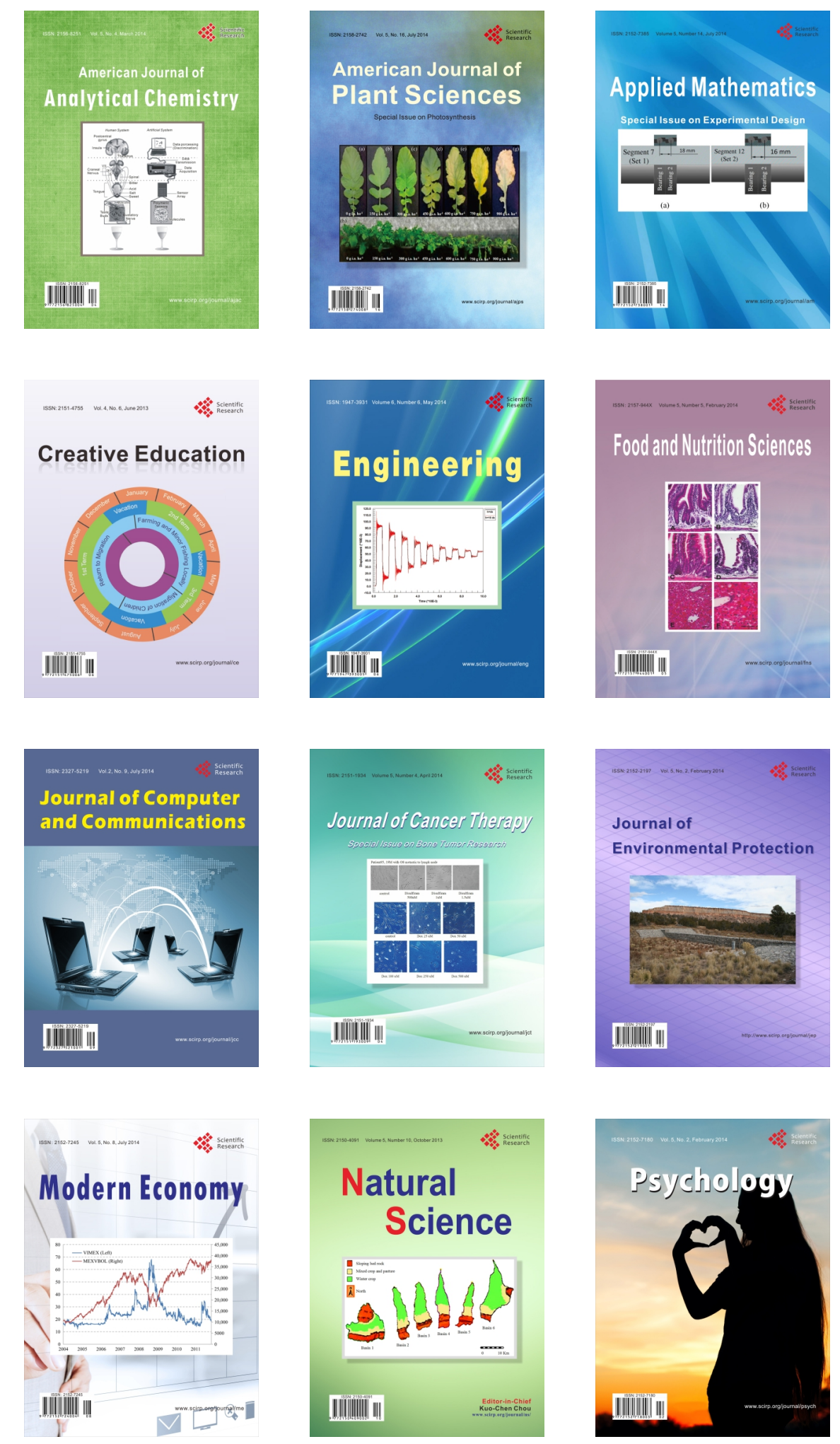